\title{
HUBUNGAN ANTARA PENAMBAHAN BERAT BADAN IBU SELAMA HAMIL DENGAN ANTROPOMETRI (BERAT BADAN, PANJANG BADAN, LINGKAR KEPALA) BAYI BARU LAHIR
}

\author{
Nuur Octascriptiriani Rosdianto ${ }^{1)}$, Herry Herman²), Vita Murniati3) \\ ${ }^{1}$ Staf Dosen Program Studi D III Kebidanan STIKes Sukabumi \\ 2Departemen Orthopedi Fakultas Kedokteran Universitas Padjadjaran \\ 3Departemen Obstetri dan Ginekologi Fakultas Kedokteran Universitas Padjadjaran \\ 1email: khanza.syakira@gmail.com \\ 2email: herry_herman@yahoo.com \\ 3email: vitalubis13@gmail.com
}

\begin{abstract}
Backgraund One of the factors that influence fetal growth is the nutritional problem in pregnant women that is associated with the right weight gain during pregnancy. Weight gain during pregnancy can affect maternal mortality, complications during pregnancy, childbirth, and mode of delivery. Weight gain during pregnancy is one of the important things in evaluating pregnancy status and predicting the weight, body length and head circumference of a newborn baby.

The purpose of this study was to determine the relationship between maternal weight gain during pregnancy with anthropometry (body weight, body length, head circumference) newborns at PONED Puskesmas Sukabumi in the Work Area of Sukabumi City.

MethodsThis study uses a comparative analytical study design with a cross sectional approach, with a sample of 72 postpartum mothers. Using secondary data in the form of data listed in the Maternal and Child Health Book (MCH). Data analysis was done using Anova followed by T-Test Unequal Variances.

The results of this study found a relationship between maternal weight gain during pregnancy in the 2nd trimester of fetal body weight $(p=0.03)$, there was a relationship between maternal weight gain during 1 st $\& 2 n d$ trimester pregnancy on the body length of newboms $(p=0.008, p=0.02)$ and there is a relationship between maternal weight gain during $2 n d \& 3 r d$ trimester pregnancy on infant's head circumference $(p=0.004, p=$ 0.004).

The conclusions of this study is that the addition of maternal weight during pregnancy in the second trimester is associated to the weight of the newborn baby. In the 1st and 2nd trimesters can be associated to the baby's body length, maternal weight gain during pregnancy in the 2nd and 3rd trimesters is associated to the baby's head circumference.

Suggestion in trimesters 2 and 3 the fetal brain and skull bones develop very rapidly, so the recommendation of adding enough weight in trimesters 2 and 3 is very important to get a fetus with a larger head circumference.
\end{abstract}

Learn to pronounce

Keywords: Maternal Weight gain during pregnancy, anthropometryof newborns

\section{ABSTRAK}

Latar Belakang Salah satu faktor yang memengaruhi pertumbuhan janin yaitu masalah nutrisi pada ibu hamil yang berhubungan dengan penambahan berat badan yang tepat selama kehamilan. Penambahan berat badan selama kehamilan dapat memengaruhi angka kematian ibu, komplikasi selama kehamilan, persalinan, dan cara persalinan. Penambahan berat badan selama kehamilan salah satu hal yang penting dalam melakukan evaluasi status kehamilan dan prediksi berat badan, panjang badan dan lingkar kepala bayi baru lahir.

Tujuan penelitian ini yaitu untuk mengetahui hubungan antara penambahan berat badan ibu selama hamil dengan antropometri (berat badan, panjang badan, lingkar kepala) bayi baru lahir di Puskesmas PONED Sukabumi Wilayah Kerja Kota Sukabumi.

Metode Penelitian ini menggunakan rancangan bersifat analitik komparatif studi dengan pendekatan cross sectional, dengan sampel 72 orang ibu nifas. Menggunakan data sekunder berupa data yang tercantum 
dalam Buku Kesehatan Ibu dan Anak (KIA). Dilakukan analisis data menggunakan Anova dilanjutkan dengan $T$ Test Unequal Variances.

Hasil penelitian terdapat hubungan antara penambahan berat badan ibu selama hamil trimester 2 terhadap berat badan janin $(\mathrm{p}=0,03)$, terdapat hubungan antara penambahan berat badan ibu selama hamil trimester $1 \& 2$ terhadap panjang badan bayi baru lahir $(p=0,008, p=0,02)$ dan terdapat hubungan antara penambahan berat badan ibu selama hamil trimester $2 \& 3$ terhadap lingkar kepala bayi $(p=0,004, p=0,004)$.

Simpulan penelitian ini adalah penambahan berat badan ibu selama hamil trimester 2 berhubungan dengan berat badan bayi baru lahir. Pada trimester 1 dan 2 dapat berhubungan dengan panjang badan bayi, penambahan berat badan ibu selama hamil pada trimester 2 dan 3 berhubungan dengan lingkar kepala bayi

Saran. Pada trimester 2 dan 3 ini otak dan tulang tengkorak janin berkembang sangat pesat, maka rekomendasi penambahan berat badan yang cukup pada trimester 2 dan 3 sangat penting untuk mendapatkan janin dengan ukuran lingkar kepala yang lebih besar.

Kata Kunci : Penambahan Berat Badan Ibu Selama Hamil, Antropometri Bayi Baru, Lahir

\section{PENDAHULUAN}

Kehamilan adalah suatu proses mengandung janin di dalam tubuh wanita, yang sebelumnya diawali dengan proses pembuahan dan kemudian akan berakhir dengan proses persalinan (Gaskin, 2014).

Masa kehamilan merupakan masa dimana ibu membutuhkan unsur gizi yang lebih banyak daripada yang diperlukan dari keadaan tidak hamil. Gizi tersebut selain diperlukan untuk memenuhi kebutuhan sendiri, juga diperlukan untuk pertumbuhan dan perkembangan janin yang ada dalam kandungannya. Asupan kebutuhan ibu hamil yang tidak tercukupi, dapat berakibat buruk bagi ibu dan janin. Janin dapat mengalami kecacatan atau lahir dengan berat badan lahir rendah (BBLR), anemia pada bayi, keguguran dan kematian neonatal (Verma A,2012).

Salah satu faktor penting terjadinya morbiditas dan mortalitas neonatal yaitu berat badan bayi baru lahir. Hal ini merupakan indikator yang sangat baik untuk mengukur status kesehatan selama periode penting pertumbuhan dan perkembangan janin (Soliman, AT, 2012). Hal penting lainnya yaitu kematian perinatal, morbiditas dan berat lahir bayi memiliki hubungan yang kuat dengan status gizi pada ibu (Verma A,2012).

Salah satu faktor yang memengaruhi pertumbuhan janin yaitu masalah nutrisi pada ibu hamil yang berhubungan dengan penambahan berat badan yang tepat selama kehamilan. Hal ini merupakan faktor penting dalam mencegah komplikasi pada ibu atau janin. Indeks masa tubuh (IMT) sebelum hamil dan penambahan berat badan selama hamil yang sesuai dapat mencegah komplikasi pada kehamilan dan masa perinatal (Nilufer Akgun, 2017).

Sementara itu penambahan berat badan ibu selama hamil memengaruhi berat badan bayi baru lahir. Indeks masa tubuh selama sebelum kehamilan yang berlebihan memiliki efek buruk pada penambahan berat badan yang direkomendasikan selama kehamilan, sehingga dapat meningkatkan komplikasi pada ibu. Asupan gizi dan penambahan berat badan selama kehamilan adalah dua faktor utama yang memengaruhi ibu dan bayi. Faktor utama yang memengaruhi penambahan berat badan ibu selama hamil adalah berat badan, tinggi badan, etnis, usia, paritas (jumlah kelahiran), kebiasaan merokok, status sosial ekonomi, dan asupan energi setiap hari (Ferraro ZM, 2012).

Penambahan berat badan selama kehamilan dapat memengaruhi angka kematian ibu, komplikasi selama kehamilan, persalinan, dan cara persalinan (Yu Z, 2013). Selain itu, penambahan berat badan yang berlebihan selama kehamilan juga berhubungan dengan kesulitan menyusui selama periode masa nifas (Matias SL, 2014). Penambahan berat badan sebelum hamil yang melebihi dari indeks massa tubuh (IMT) pada wanita hamil berhubungan dengan kejadian diabetes pada kehamilan, gangguan hipertensi, komplikasi tromboemboli, persalinan prematur, makrosomia (Gaskin AJ, 2014).

\section{METODOLOGI PENELITIAN}

Rancangan penelitian analitik komparatif studi dengan pendekatan cross sectional.

\section{Populasi dan Sampel Penelitian}

Populasi penelitian eluruh ibu nifas yang berada di Kota Sukabumi, sampel sebanyak 72 ibu nifas yang terdiri dari 24 ibu yang memiliki riwayat penambahan berat badan kurang, 24 ibu memiliki riwayat ibu yang memiliki riwayat penambahan berat badan cukup, 24 ibu memiliki riwayat ibu yang memiliki riwayat penambahan berat badan lebih 
dan memiliki buku KIA yang melakukan antenatalcare minimal 4 kali ( 1 kali pada trimester 1, 1 kali pada trimester 2 dan 2 kali pada trimester 3) dan melahirkan di Puskesmas PONED Sukabumi dengan teknik pengambilan sampel menggunakan simple random sampling (Sopiyudin, 2013).

\section{Metode Pengumpulan Data}

Jenis data yang digunakan dalam penelitian ini adalah data sekunder. Instrumen pengumpulan data berdasarkan data yang tercantum pada Buku $\mathrm{KIA}$. Analisis data yang digunakan adalah analisis univariabel dan bivaribel. Analisis bivariabel menggunakan ANOVA dilanjutkan menggunakan $T$ Test unequal variances (Sopiyudin, 2013).

\section{HASIL PEMBAHASAN}

\section{Tabel 1 Karakteristik Subjek Penelitian Berdasarkan Penambahan Berat Badan Ibu Selama Hamil}

\begin{tabular}{|c|c|c|c|c|c|c|}
\hline \multirow{3}{*}{ Karakteristik ibu } & \multicolumn{6}{|c|}{ Penambahan Berat Badan Ibu Selama Hamil } \\
\hline & \multicolumn{2}{|c|}{$\begin{array}{l}\text { Kurang } \\
(n=24)\end{array}$} & \multicolumn{2}{|c|}{$\begin{array}{l}\text { Cukup } \\
(n=24)\end{array}$} & \multicolumn{2}{|c|}{$\begin{array}{l}\text { Lebih } \\
(n=24)\end{array}$} \\
\hline & $\mathrm{N}$ & $\%$ & $\mathrm{~N}$ & $\%$ & $\mathrm{n}$ & $\%$ \\
\hline \multicolumn{7}{|l|}{ Umur (tahun) } \\
\hline 1. $<20$ tahun & 0 & 0 & 1 & 4,2 & 1 & 4,2 \\
\hline 2. 20-35 tahun & 23 & 95,8 & 22 & 91,7 & 21 & 87,5 \\
\hline 3. >35tahun & 1 & 4,2 & 1 & 4,2 & 2 & 8,3 \\
\hline \multicolumn{7}{|l|}{ IMT ibu } \\
\hline 1. Kurang $(<18,5)$ & 7 & 29,2 & 2 & 8,3 & 3 & 12,5 \\
\hline 2. Normal $(18,5-24,9)$ & 14 & 58,3 & 12 & 50,0 & 9 & 37,5 \\
\hline 3. Overweight $(25,0-29,9)$ & 3 & 12,5 & 7 & 29,2 & 10 & 41,7 \\
\hline 4. Obesitas $(\geq 30,0)$ & 0 & 0 & 3 & 12,5 & 2 & 8,3 \\
\hline \multicolumn{7}{|l|}{ Paritas } \\
\hline 1. 1 & 8 & 33,3 & 8 & 33,3 & 12 & 50 \\
\hline 2. $2-3$ & 13 & 54,2 & 16 & 66,7 & 12 & 50 \\
\hline 3. $\geq 4$ & 3 & 12,5 & 0 & 0 & 0 & 0 \\
\hline \multicolumn{7}{|l|}{ Pendidikan } \\
\hline 1. Pendidikan tinggi $>12$ tahun & 3 & 12,5 & 0 & 0 & 2 & 8,3 \\
\hline 2. Pendidikan menengah 12 tahun & 13 & 54,2 & 10 & 41,7 & 11 & 45,8 \\
\hline 3. Pendidikan dasar 9 tahun & 8 & 33,3 & 14 & 58,3 & 11 & 45,8 \\
\hline \multicolumn{7}{|l|}{ Pekerjaan } \\
\hline 1. Bekerja & 6 & 25 & 3 & 12,5 & 2 & 8,3 \\
\hline 2. Tidak bekerja & 18 & 75 & 21 & 87,5 & 22 & 91,7 \\
\hline \multicolumn{7}{|l|}{ Status Ekonomi(penghasilan) } \\
\hline 1. $\geq U M R$ & 14 & 58,3 & 3 & 12,5 & 2 & 8,3 \\
\hline 2. $<$ UMR & 10 & 41,7 & 21 & 87,5 & 22 & 91,7 \\
\hline \multicolumn{7}{|l|}{ Kadar Hb Ibu hamil } \\
\hline 1. Anemia (<11gr/dl) & 6 & 25,0 & 4 & 16,7 & 3 & 12,5 \\
\hline 2. Tidak Anemia ( $\geq 11 \mathrm{gr} / \mathrm{dl})$ & 18 & 75,0 & 20 & 83,3 & 21 & 87,5 \\
\hline
\end{tabular}

Tabel 2 Berat Badan Bayi Baru Lahir Berdasarkan Penambahan Berat Badan Ibu Selama Hamil Pada Trimester 1, 2 dan 3

\begin{tabular}{ccccc}
\hline Penambahan BB & \multicolumn{3}{c}{ Berat Badan Bayi Baru Lahir } & \multirow{2}{*}{ Nilai $\mathrm{p}^{*}$} \\
\cline { 2 - 4 } Ibu Selama Hamil & Kurang $(\mathrm{n}=24)$ & \multicolumn{1}{c}{ Cukup $(\mathrm{n}=24)$} & Lebih $(\mathrm{n}=24)$ & \\
\hline Trimester 1 & $3079,17 \pm 172$ & $3183,3 \pm 188$ & $3056,25 \pm 180$ & 0,57 \\
Trimester 2 & $2922,9 \pm 176$ & $3240,3 \pm 161^{* *}$ & $3147,7 \pm 184^{* *}$ & $0,03^{*}$ \\
Trimester 3 & $3214,5 \pm 176$ & $3089,5 \pm 157$ & $3214,5 \pm 199$ & 0,2 \\
\hline
\end{tabular}

Keterangan : *) nilai $p<0,05$ dihitung berdasarkan uji Anova dilanjutkan dengan $T$-Test Unequal Variances

**) Pada trimester 2 kelompok cukup $n=26$, pada kelompok lebih $n=22$ 
Tabel 3 Analisis Uji Beda Berat Badan Bayi Baru Lahir Berdasarkan Penambahan Berat Badan Ibu Selama Hamil Pada Kelompok Ibu Kurang, Cukup dan Lebih

\begin{tabular}{cccc}
\hline $\begin{array}{c}\text { Penambahan BB } \\
\text { Ibu Selama Hamil }\end{array}$ & $\begin{array}{c}\text { Bbu Kurang } \\
\text { Vs } \\
\text { Ibu Cukup }\end{array}$ & $\begin{array}{c}\text { Ibu Kurang } \\
\text { Vs } \\
\text { Ibu Lebih }\end{array}$ & $\begin{array}{c}\text { Ibu Cukup } \\
\text { Vs } \\
\text { Ibu Lebih }\end{array}$ \\
\hline Trimester 2 & $0,01^{*}$ & 0,08 & 0,45 \\
\hline
\end{tabular}

Keterangan : *) nilai $p<0,05$ dihitung berdasarkan uji T-Test Unequal Variances

Tabel 4 Panjang Badan Bayi Baru Lahir Berdasarkan Penambahan Berat Badan Ibu Selama Hamil Pada Trimester 1, 2 dan 3

\begin{tabular}{ccccc}
\hline \multirow{2}{*}{$\begin{array}{c}\text { Penambahan BB Ibu } \\
\text { Selama Hamil }\end{array}$} & \multicolumn{3}{c}{ Panjang Badan Bayi Baru Lahir } & \multirow{2}{*}{ Nilai $\mathrm{p}^{*}$} \\
\cline { 2 - 4 } & Kurang(n=24) & Cukup(n=24) & Lebih(n=24) & \\
\hline Trimester 1 & $48,7 \pm 0,7$ & $50,12 \pm 0,85$ & $48,5 \pm 0,75$ & $0,008^{*}$ \\
Trimester 2 & $48,29 \pm 0,7$ & $49,8 \pm 0,67^{* *}$ & $49,2 \pm 0,9^{* *}$ & $0,02^{*}$ \\
Trimester 3 & $49 \pm 0,88$ & $49,2 \pm 0,68$ & $49,2 \pm 0,88$ & 0,91 \\
\hline
\end{tabular}

Keterangan : *) nilai $p<0,05$ dihitung berdasarkan uji Anova dilanjutkan dengan T-Test Unequal Variances

**) Pada trimester 2 kelompok cukup $n=26$, pada kelompok lebih $n=22$

Tabel 5 Analisis Uji Beda Panjang Bayi Baru Lahir Berdasarkan Penambahan Berat Badan Ibu Selama Hamil Pada Kelompok Ibu Kurang, Cukup dan Lebih

\begin{tabular}{cccc}
\hline & \multicolumn{3}{c}{ Panjang Badan Bayi Baru Lahir } \\
\cline { 2 - 4 } Penambahan BB & Ibu Kurang & lbu Kurang & Ibu Cukup \\
Ibu Selama Hamil & Vs & Vs & Vs \\
& Ibu Cukup & Ibu Lebih & lbu Lebih \\
\hline Trimester 1 & $0,014^{*}$ & 0,74 & $0,007^{*}$ \\
Trimester 2 & $0,004^{*}$ & 0,13 & 0,35 \\
\hline
\end{tabular}

Keterangan : *) nilai $p<0,05$ dihitung berdasarkan uji T-Test Unequal Variances

Tabel 6 Lingkar Kepala Bayi Baru Lahir Berdasarkan Penambahan Berat Badan Ibu Selama Hamil Pada Trimester 1, 2 dan 3

\begin{tabular}{ccccc}
\hline Penambahan Berat & \multicolumn{3}{c}{ Lingkar Kepala Bayi Baru Lahir } & \multirow{2}{*}{ Nilai $\mathrm{p}^{*}$} \\
\cline { 2 - 4 } $\begin{array}{c}\text { Badan Ibu Selama } \\
\text { Hamil }\end{array}$ & Kurang $(\mathrm{n}=24)$ & Cukup $(\mathrm{n}=24)$ & Lebih $(\mathrm{n}=24)$ & \\
\hline Trimester 1 & $31,25 \pm 0,94$ & $31 \pm 0,97$ & $31,6 \pm 1,18$ & 0,68 \\
Trimester 2 & $30 \pm 0,83$ & $31,87 \pm 0,93^{* *}$ & $32,18 \pm 1,18^{* *}$ & $0,004^{*}$ \\
Trimester 3 & $31,08 \pm 0,99$ & $30,29 \pm 0,90$ & $32,58 \pm 0,99$ & $0,004^{*}$ \\
\hline
\end{tabular}

Keterangan : *) nilai $p<0,05$ dihitung berdasarkan uji Anova dilanjutkan dengan T-Test Unequal Variances .

**) Pada trimester 2 kelompok cukup $n=26$, pada kelompok lebih $n=22$

Tabel 7 Analisis Uji Beda Lingkar Kepala Bayi Baru Lahir Berdasarkan Penambahan Berat Badan Ibu Selama Hamil Pada Kelompok Ibu Kurang, Cukup dan Lebih

\begin{tabular}{cccc}
\hline Penambahan Berat & \multicolumn{3}{c}{ Lingkar Kepala Bayi Baru Lahir } \\
\cline { 2 - 4 } Badan Ibu Selama & Ibu Kurang & Ibu Kurang & Ibu Cukup \\
Hamil & Vs & Vs & Vs \\
& Ibu Cukup & lbu Lebih & Ibu Lebih \\
\hline Trimester 2 & $0,004^{*}$ & $0,004^{*}$ & 0,69 \\
Trimester 3 & 0,24 & $0,039^{*}$ & $0,001^{*}$ \\
\hline
\end{tabular}

Keterangan : *) nilai $p<0,05$ dihitung berdasarkan uji T-Test Unequal Variances 
Data karakteristik pada subjek penelitian meliputi usia, IMT, paritas, pendidikan, pekerjaan, status ekonomi dan kadar $\mathrm{Hb}$ pada ibu. Pada tabel 4.1 sebagian besar subjek pada uasia 20-35 tahun, sebagian besar memiliki IMT normal dan overweight, sebagian besar paritas 2-3, sebagian mengenyam pendidikan menengah 12 tahun dan pendidikan dasar 9 tahun, sebagian besar tidak bekerja, sebagian memiliki status ekonomi (penghasilan) kurang dari UMR dan sebagian tidak anemia.

Berdasarkan tabel 2 didapatkan hasil terdapat hubungan antara penambahan berat badan ibu selama hamil trimester 2 dengan berat badan bayi baru lahir dengan $p$-value 0,03 . Sedangkan pada trimester 1 dan 3 tidak terdapat hubungan dengan $p$-value $>0,05$. Hasil analisis uji beda pada kelompok penambahan berat badan ibu selama hamil yang cukup dan kurang terdapat perbedaan dengan hasil $p$-value 0,01 .

Pada kajian teori diketahui bahwa pada trimester 1 penambahan berat badan ibu hampir seluruhnya merupakan kenaikan berat badan ibu, belum dipengaruhi oleh pertumbuhan janin. Fisik janin juga mulai terbentuk pada bulan pertama. Pada trimester 2 sebesar $60 \%$ dari penambahan berat badan ini disebabkan pertumbuhan jaringan ibu dan pada trimester 3 sebesar $60 \%$ dari penambahan berat badan karena pertumbuhan jaringan janin (Lumbers ER, 2014).

Bertambahnya berat badan ibu selama hamil menggambarkan status gizi selama hamil, oleh karena itu perlu dipantau setiap bulan. Jika terdapat kelambatan dalam penambahan berat badan ibu terus menerus, ini dapat menandakan adanya malnutrisi sehingga dapat menyebabkan gangguan pertumbuhan janin intrauterine (Societa,2014). Hal ini sesuai dengan hasil penelitian yang dilakukan oleh Crane, 2009 bahwa terdapat hubungan antara penambahan berat badan ibu hamil tersebut dengan antropometri bayi baru lahir (Crane JMG, 2014).

Berdasarkan tabel 3 didapatkan hasil terdapat hubungan antara penambahan berat badan ibu selama hamil trimester 1 dan 2 dengan panjang badan bayi baru lahir yaitu panjang bayi dengan masing-masing $p$-value 0,008 dan 0,02. Sedangkan pada trimester 3 tidak terdapat hubungan antara penambahan berat badan ibu selama hamil terhadap panjang badan bayi baru lahir dengan $p$-value 0,91 . Hasil analisis uji beda trimester 1 dan 2 pada kelompok penambahan berat badan ibu selama hamil yang cukup dan kurang terdapat perbedaan dengan hasil $p$-value 0,014 dan 0,004 . Hasil analisis uji beda trimester 3 pada kelompok penambahan berat badan ibu selama hamil yang cukup dan lebih terdapat perbedaan dengan hasil $p$-value 0,007 .

Selain itu, hasil penelitian ini sesuai dengan penelitian yang dilakukan oleh Jayanthi pada tahun 2015 mengenai korelasi antara antropometri ibu dan ukuran bayi baru lahir dengan hasil, terdapat korelasi antara indeks massa tubuh ibu dengan panjang badan bayi baru lahir dengan $r=0,333$ dan p-value 0,019 (Srikanth, 2015).

Penambahan berat badan ibu yang cukup pada trimester 1 dan 2 memengaruhi panjang badan bayi baru lahir. Hal ini disebabkan oleh pertumbuhan tulang-tulang janin pada trimester ini terutama trimester 2 mengalami pertumbuhan yang optimal dibandingkan dengan pertumbuhan dan perkembangan otaknya. Sehingga penting sekali pemantauan penambahan berat badan ibu selama hamil pada setiap trimester untuk mendapatkan bayi yang sehat dan normal. Rekomendasi penambahan berat badan yang cukup pada trimester 1 dan 2 sangat penting untuk mendapatkan janin dengan ukuran tubuh lebih tinggi.

Berdasarkan tabel 4 didapatkan hasil terdapat hubungan yang bermakna antara penambahan berat badan ibu selama hamil pada trimester 2 dan 3 dengan lingkar kepala bayi baru lahir dengan $p$-value masing-masing 0,004. Pada trimester 2, kelompok penambahan berat badan selama hamil yang kurang rata-rata lingkar kepala bayi $30 \pm 0,83 \mathrm{~cm}$, pada kelompok cukup rata-rata lingkar kepala bayi $31,8 \pm 0,93 \mathrm{~cm}$, pada kelompok lebih rata-rata lingkar kepala bayi $32,18 \pm 1,18 \mathrm{~cm}$. Sedangkan pada trimester 3, kelompok penambahan berat badan selama hamil yang kurang rata-rata lingkar kepala bayi $31,08 \pm 0,99 \mathrm{~cm}$, pada kelompok cukup rata-rata lingkar kepala bayi $30,29 \pm 0,9 \mathrm{~cm}$, pada kelompok lebih rata-rata lingkar kepala bayi $32,58 \pm 0,99 \mathrm{~cm}$. Sedangkan pada trimester 1 tidak terdapat hubungan dengan $p$-value $>0,05$

Hasil penelitian ini sesuai dengan penelitian yang dilakukan oleh Crane pada tahun 2009 yaitu kenaikan berat badan selama hamil dibawah rekomendasi IOM berkaitan dengan tingkat kelahiran berat lahir rendah yang lebih tinggi dan lingkar kepala bayi yang kurang dari $35 \mathrm{~cm}$ (Crane JMG, 2014).

Selain itu terdapat hasil penelitian lain yang dilakukan oleh Jayanthi pada tahun 2015 mengenai korelasi antara antropometri ibu dan ukuran bayi baru lahir dengan hasil, terdapat korelasi antara indeks massa tubuh ibu dengan lingkar kepala bayi baru lahir (Srikanth, 2015). 
Karena pada trimester 2 dan 3 ini otak dan tulang tengkorak janin berkembang sangat pesat, maka rekomendasi penambahan berat badan yang cukup pada trimester 2 dan 3 sangat penting untuk mendapatkan janin dengan ukuran lingkar kepala yang lebih besar.

\section{KETERBATASAN PENELITIAN}

Pada penelitian ini tidak membahas pola makan, kualitas makro dan mikronutrien yang di konsumsi oleh subjek penelitian. Pada penelitian ini juga menggunakan data sekunder sehingga tidak bisa mengontrol kesalahan interobserver dan intraobserver pada saat dilakukan pengukuran antropometri bayi baru lahir dan untuk penelitian selanjutnya disarankan menggunakan metode kohort dengan data primer. Lokasi tempat penelitian yang diambil hanya di Puskesmas PONED Sukabumi Wilayah Kerja Kota Sukabumi, sehingga belum dapat menggambarkan keadaan penambahan berat badan rata-rata ibu hamil dan antropometri bayi baru lahir secara keseluruhan di daerah Kota Sukabumi.

\section{KESIMPULAN DAN SARAN}

Terdapat hubungan antara penambahan berat badan ibu selama hamil pada trimester 2 terhadap berat badan bayi baru lahir, sedangkan pada trimester 1 dan 3 tidak terdapat hubungan. Terdapat hubungan antara penambahan berat badan ibu selama hamil pada trimester 1 dan 2 terhadap panjang badan bayi baru lahir, sedangkan pada trimester 3 tidak terdapat hubungan. Terdapat hubungan antara penambahan berat badan ibu selama hamil pada trimester 2 dan 3 terhadap lingkar kepala bayi baru lahir, sedangkan pada trimester 1 tidak terdapat hubungan.

Diharapkan dapat terus melakukan pemantauan penambahan berat badan ibu selama hamil trimester 1, 2 dan 3 berdasarkan rekomendasi IOM sesuai panduan WHO. Memberikan edukasi kepada pasangan usia subur untuk memperhatikan IMT sebelum hamil, jika IMT kurang sebelum hamil, maka lebih baik mempersiapkan status gizi dan nutrisi terlebih dahulu dan jika berlebih maka disarankan mengurangi berat badan sebelum terjadi kehamilan. Sehingga dapat mengontrol penambahan berat badan ibu yang sesuai untuk pertumbuhan janin yang normal selama kehamilan dan meminimalkan penambahan berat badan yang berlebihan atau kurang yang dapat berisiko terhadap ibu maupun pertumbuhan dan perkembangan janin salah satunya dengan menerapkan pemilihan makanan dengan gizi yang seimbang.

\section{DAFTAR PUSTAKA}

Crane JMG, White J, Murphy P, Burrage L, Hutchens D. The effect of gestational weight gain by body mass index on maternal and neonatal outcomes. J Obstet Gynaecol Can JOGC J Obstétrique anaemia and pregnancy outcome in assam, India. 2014. BMJ Global Health.

Ferraro ZM, Barrowman N, Prud Homme D, Walker $M$, Wen SW, Rodger M, et al. Excessive gestational weight gain predicts large for gestational age neonates independent of maternal body mass index. J Matern Fetal Neonatal Med. 2012;25:538-542. PubMed.

Gaskins AJ, Rich Edwards JW, Colaci DS, Afeiche $M C$, Toth TL, Gillman MW, et al. Prepregnancy and early adulthood body mass index and adult weight change in relation to fetal loss. Obstet Gynecol. 2014;124:662-669. PubMed.

Lumbers ER, Pringle KG. 2014. Roles of the circulating renin-angiotensin-aldosterone system in human pregnancy. Am J Physiol Regul Integr Comp Physiol. 2014 Jan 15; 306(2):R91-101

Matias SL, Dewey KG, Quesenberry CP, Gunderson EP. Maternal prepregnancy obesity and insulin treatment during pregnancy are independently associated with delayed lactogenesis in women with recent gestational diabetes mellitus. Am J Clin Nutr. 2014;99:115-121. PubMed

Nilufer Akgun, MD, Huseyin L. Keskin, MD, Isık Ustuner, MD, Gulden Pekcan, MD, and Ayse F. Avsar, MD. Factors affecting pregnancy weight gain and relationships with maternal/fetal outcomes in Turkey. (PMID:28439600 PMCID:pmc5447211). Saudi Med J. 2017 May; 38(5): 503-508

Srikanth, Jayanthi , Ashwini Kumari. To study the correlation between maternal anthropometric measurements and new born birth size.RGUHS Med Sciences, January 2015/ vol. 5/issue 1.

Società di Nutrizione Umana (SINU) LARN-Livelli di Assunzione di Riferimento di Nutrienti ed Energia per la Popolazione Italiana. SICS; Milano, Italy: 2014. pp. 1-655. IV Revisione. 
Soliman, AT, Eldabbagh, M, Saleem, W, Zahredin, $\mathrm{K}$, Shatla $\mathrm{E}$ and Adel A. Placental weight: Relation to maternal weight and growth parameters of full-term babies at birth and during childhood. Arch Dis Child. 2012;97:A189

Sopiyudin, Dahlan. 2013. Besar sampel dan cara pengambilan sampel dalam penelitian kedokteran dan kesehatan. Jakarta : Salemba Medika.
Verma A, Shrimali L. Maternal body mass index and pregnancy outcome. J Clin Diagn Res. 2012;6(9):1531-33.

Yu Z, Han S, Zhu J, Sun X, Ji C, Guo X, et al. Prepregnancy body mass index in relation to infant birth weight and offspring overweight/obesity: a systematic review and meta-analysis. PloS One. 2013;8:e61627. PubMed 